\title{
Effects of methyl parathion on Oscimum americanum L. infected with fungus Fusarium oxysporum
}

\author{
K.K. Mishra \\ Department of Botany, M.M.A.M. Campus, T.U., Biratnagar, Nepal
}

Key words: Fusarial wilt, methyl parathion, Oscimum americanum, next generation plants.

The pathogen Fusarium oxysporum during its different stages of growth-mycelia, mat of mycelia, microconidia and megaconidia-liberates several toxic substances that either inactivate the cells or lysis of even xylem and phloem tissues of the host plant Oscimum americanum. The most notorious toxin is the fusaric acid that causes vein clearing, epinasty, reduction in respiration and growth, necrosis of cortical cells overlying vascular bundles, furrowing of stem, deposition of salts on stem and sometimes bending of the stem (Sundaram, 1970; Mishra, 2008; 2013). Present study O. americanum exhibited some distinct symptoms of fusarial wilt (Table 1).

Table 1. Symptoms of Fusarium wilt in Oscimum americanum.

\begin{tabular}{ccl}
\hline Plant height $(\mathbf{c m})$ & Number of branches & Symptoms \\
\hline 60 & 16 & Less white; \\
55 & 11 & Vascular tissus white; \\
35 & 9 & Breakage of xylem \& phloem tissues.
\end{tabular}

Presence of spores in epidermal and vascular regions:

a. Smallest twig: micro \& megaconidia 1 each; microconidium unicellular; mycelium present.

b. Intermediate twig: megaconidium one (5-septate); mycelium sometimes absent.

c. Largest twig: micro and megaconidium present in the cortical region; mycelium most often present.

The host plant and its surroundings were sprayed with the fungicide methyl parathion for cure for fusarial wilt. Seeds of the cured plants were sown in earthen pots. The leaves of these grown plants were counted 75 days after sowing for leaf colour. The leaf colour of the parent plant was red but next generation plants had red and green colour in the range of 5-95\%. Thus, the fungicide methyl parathion although controlled the fusarial disease, nevertheless it appeared to be responsible for changes in leaf colour (from red to green) to some extent in next generation.

\section{References}

Mishra, K.K. 2008. Date palm without date due to Fusarium Oxysporum var. Toddy in eastern zone of Nepal. 95 ${ }^{\text {th }}$ Indian Science Congress, Jan 3-7, 2008, Vishakhapatnum. 87p.

Mishra, K.K. 2013. The fungicide around the fusarial conidia of Ocimum americanum L. at Biratnagar Nepal. Abstract, $100^{\text {th }}$ Indian Science Congress, Vishakhapatanum, Jan 3-7. $100^{\text {th }}$ Indian Science Congress, Kolkata, Jan 3-7. 98p.

Sundram, R.K. 1970. Mode of action of fusaric acid' in plant disease problems, Proc. I Int. symp. Pl. pathology, IARI, New Delhi. pp 135-142. 